\title{
KU School of Medicine Mission-Based Allocation Model: Aligning Funding with Expectations
}

\section{Peter G. Smith, PhD, Senior Associate Dean for Research \\ John H. Wineinger MD Professor of Molecular and Integrative Physiology \\ School of Medicine \\ University of Kansas Medical Center \\ psmith@kumc.edu}

7 he past decade has been challenging for public universities that rely predominantly on state funding for their general operations. Most have seen significant and sustained decreases in state funding. As demands have grown for other programs, higher education funding has declined; since 2008, per student spending has declined in nearly all states, in some cases exceeding $50 \%{ }^{1-3}$.

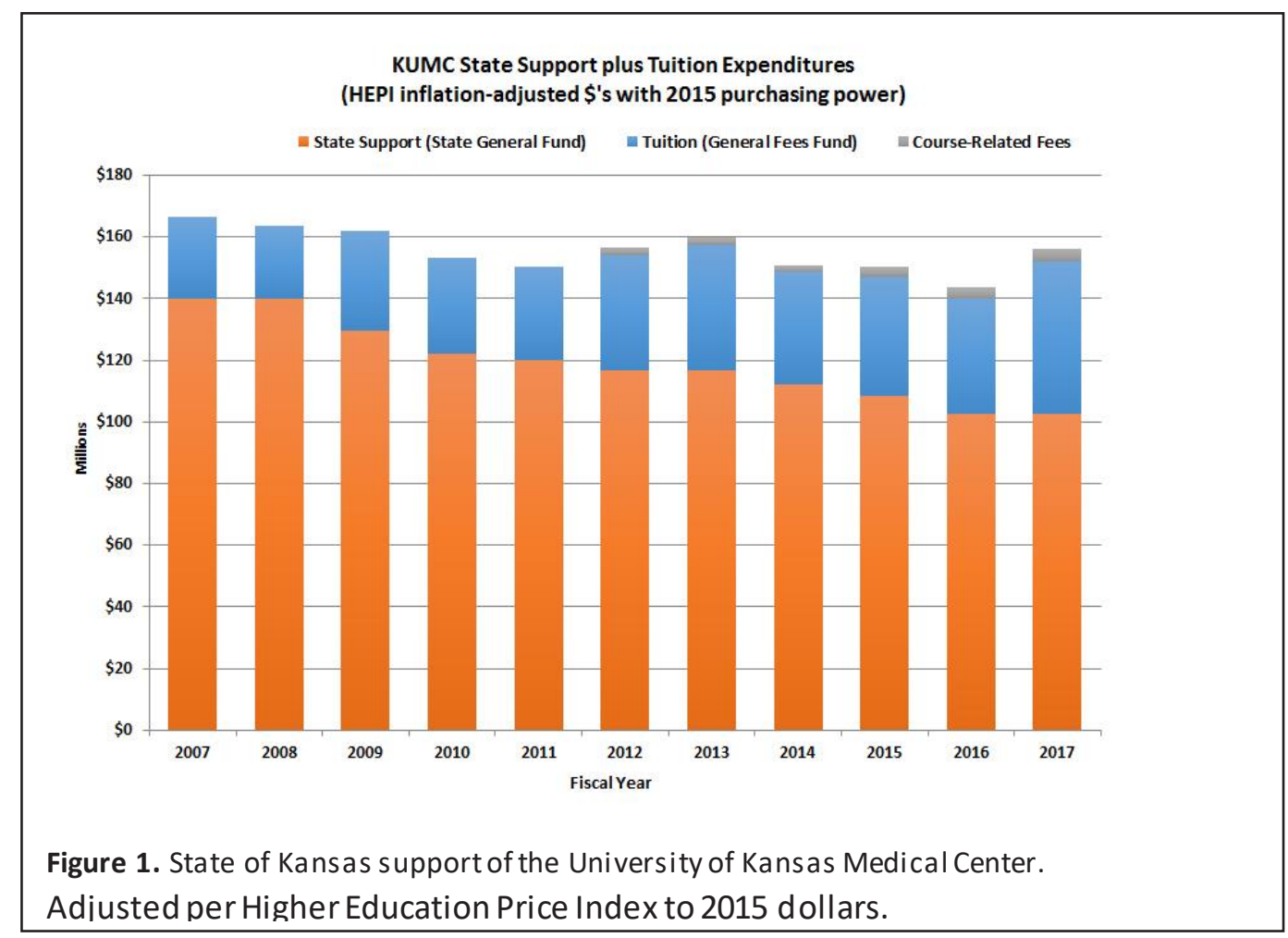

Medical schools have not been spared. In the case of the University of Kansas School of Medicine (KU SOM), state support declined nearly every year between 2007 and 2017. In 2017, the inflation-adjusted annual state allotment to the University of Kansas Medical Center was $\$ 40 \mathrm{M}$ less than it was in 2007 (Figure 1). To some extent, this decrease was offset by increases in revenue from tuition and fees, such that the decrease in overall funding was approximately $7 \%$. However, during this period student enrollment increased by $23 \%$. The decline in state funding at a time of expanding demand forced University leadership to reconsider how financial resources should be distributed so that they best align with the school's missions in terms of research, education, and service. 


\section{The 'historical' funding model}

Like many schools, faculty salaries at KU SOM were based on an historical model. State funds were designated to support individuals - that is, a 'state line' was provided for a particular faculty member based on prior years' allocations, adjusted to reflect any major changes in overall funding from the state.

The historical funding model had certain advantages. Perhaps foremost is its predictability. Although some sources of salary support, such as effort on federal and foundation grants, research contracts and clinical trials, are not fixed, the bulk were relatively stable under the historical model. This facilitates financial planning at the departmental and personal level and provides an assuring measure of predictability to chairs developing their departmental budgets. However, the historical model has two very significant shortcomings. First, not all historical salary lines were created equally. Faculty who were recruited in better times when state funding was high, tended to hold more robust lines which were less dependent on external resources, and were further augmented by state-mandated raises (a rare occurrence in recent years). In contrast, recruitments that took place more recently, when less state funding was available, depended more on riskier external resources to make up larger proportions of their salary. This shift toward funding proportionately less salary with state resources has been further compounded by a relative absence of raises associated with state salary dollars. Thus, within the historical model we see considerable variance in state commitment. While this may not be problematic in good times, when external funding is lost these more recent hires are impacted disproportionately and see greater reductions in salary support. Because the numbers of women and minorities recruited to academic medical schools have increased substantially in recent years, the historical model carries with it the potential for de facto wage discrimination to these groups.

Another limitation of the historical model is that it does not necessarily reflect levels of productivity or support for the School's missions. While chairs did hold the power to adjust salaries in the KU SOM historical model, these were difficult discussions and departments frequently lacked clear compensation plans that could drive the outcome. The lack of a relationship between effort and compensation vis a vis the historical model did lead to very real discrepancies in compensation for individuals performing comparable duties. Inevitably, such discrepancies lead to a perception of unfairness and faculty dissatisfaction, which in turn can lead to lowered productivity and/or problems in faculty retention.

A particular limitation of the historical model, applicable to the present situation where budget cuts are the norm, lies in how the reductions are applied. In this model, budgetary cuts are typically implemented as across the board reductions to mid-level units (departments). While a chair could choose to apply cuts in accord with specific formulae, this traditionally has not been the case. Accordingly, individuals or units that are seeing higher levels of productivity are negatively impacted to the same extents as those who are not as productive.

Transition to a mission-based funding allocation model

In the early part of the current decade, school leadership was faced with making a decision: given the probability of more budget cuts, should KU SOM 
maintain the historical allocation model or transition to a model that is fairer and better encourages faculty to focus on activities that are directly aligned with the School's mission and goals? The decision was made to abandon the historical model and replace it with a new mission-based funding allocation model that encourages alignment with the school's missions and values; a similar approach was piloted previously on a departmental level ${ }^{4}$. The mission-based allocation model would selectively distribute available funds in proportion to performance with respect to fulfilling the missions of the department and school. The objectives of the missionbased allocation model were to: 1) encourage advancement of educational and research missions; 2) better align funding with productivity; 3) reward and retain the highest producers; and 4) provide tools to ensure sustained successes of departments and the school. In developing the mission-based funding allocation model, the architects applied several primary overarching assumptions to ensure that the system would be fair, transparent, equitable, and reflect market realities. These include:

i) Funds are not allocated to individuals but go as a block grant to the department. Funds are not directly linked to individual faculty by the school but rather are intended to reflect the overall productivity of the department.

ii) All relevant faculty activities are considered to fall into 3 categories: education, research and service. Service does not include clinical service, which is reimbursed separately under a Physicians' Service Agreement with the KU Health System.

iii) Educational effort includes Undergraduate Medical Education (UME) and graduate level (Master's and $\mathrm{PhD}$ ) educational activities conducted within the School. Graduate Medical Education (GME) is funded separately from the KU Health System and is not included in the model. Allocation for educational activity is the sum of the time spent actively engaged in the activity plus a pre-determined amount of time for preparation.

iv) Research value is based on documented externally funded effort. While we recognize that effort is expended on activities that are not externally funded, a purpose of the model is to drive and prioritize efforts aimed at procuring external awards. Because funds flow to the department as a block grant and are not directly associated with specific activities, chairs vis a vis their departmental compensation plans can use research-value allocated funds to support activities not directly funded by the model but which are valued by the department.

v) Service is considered to be aligned with either educational or research domains. A fixed percentage (10\%) of computed research and educational effort is added to the total to reflect service effort.

vi) For the purposes of establishing appropriate valuations, all salary benchmarks are set as the median for a given academic faculty rank in a specific discipline in accordance with the AAMC salary survey data for Midwest public medical schools. To reduce variability (in particular any year to year decreases), we take the average for the preceding 3 years and apply an inflationary adjustment of $4 \%$. 
vii) All determinations assume that the work year (1.0 FTE) comprises 2070 hours (52 weeks minus 6 weeks vacation /holiday/ sick, with a work week of 45 hours).

viii) For activities easily tied to a given faculty member such as research effort, the allocation value is computed based on the actual rank. For activities that are more difficult to assign to a given faculty and/or may change with some frequency (e.g., didactic teaching), the weighted average rank within the department is used to compute the salary benchmark.

ix) Departments are expected to develop their own salary compensation plans that best align with the values within the department, as determined by a faculty-driven plan. This is encouraged to vary from that of the SOM allocation model in order to better reflect departmental values and promote department financial sustainability.

\section{Educational value}

The education of medical students and graduate students is one of $\mathrm{KU}$ SOM's primary missions and is acknowledged as such within the allocation model. We based the value associated with educational activities on national benchmarks and on discussion and input from individuals who have intimate knowledge of the activities in question. Table 1 depicts examples of primary activities valued under the model and the relative effort assigned to them.

The values ascribed to a given department are derived from an online educational course tracking software tool which provides information as to numbers of students, credit hours, instructors and department of record, etc. These data are refreshed proactively based on any anticipated changes in instructional activities involving UME and graduate school teaching.

\section{Table 1. Major Drivers of Educational Values}

- Didactic lectures in medical and graduate curricula

- 1 hour medical school or graduate school lecture +3 hours preparation

- Upper-level didactic course directorships based on class size:

- $\quad<10$ students $=4 \mathrm{hr}$ multiplier;10-25 = $5 \mathrm{hr}$; $>25=6 \mathrm{hr}, \mathrm{X}$ credit hours, $\mathrm{X}$ weeks (0.1-0.15FTE)

- Educational leadership receives additional credit

- E.g., Program Director $=0.1 \mathrm{FTE}+10 \mathrm{~h} /$ student

- $\mathrm{PhD}$ mentor $=0.1 \mathrm{FTE} ; \mathrm{MS}$ mentor=0.05FTE

- Educational service computed as $10 \%$ of total educational effort 
Research Value

Research value is based on effort devoted to externally funded research activities. These include studies funded by the National Institutes of Health, foundations, clinical trials, and research contracts. For inclusion as validated research effort, 3 criteria must be met:

1) the effort must be explicitly committed, such that a level of actual effort is specified in an external or internal contract that is approved by our Research Institute and school administration, 2) funds in the form of salary support must be derived directly from the project and allocated to the faculty member in proportion to the committed effort (which may be capped as appropriate to the policy of the funding agency); 3) the paid effort must be certified by the investigator at regular intervals and corrected if in error. Research effort includes roles as principal, multi- or coinvestigator or any other roles as Key Personnel, core director, center director, research mentor, etc. This allocation component to the department, reflecting funded effort, can be appropriately viewed as a research incentive.

Certified committed effort is matched incrementally up to 0.35 FTE on a one-to-one basis at the applicable salary benchmark. Thus, for an investigator committing 1 calendar month to a project, the department would receive 0.083 FTE of the rank and disciplinespecific AAMC benchmark for the faculty member in question. For an investigator with 0.35FTE committed effort, the value is 0.35 , and for a PI with 0.7FTE committed effort, the value would also be 0.35 FTE at the benchmark.

Eligibility of different academic tracks for participation in the missionbased model

KU SOM has a number of function-specific faculty tracks that are tailored to the many roles of faculty at an academic medical center. These include a clinical track (sole or primary focus on patient care and Health System responsibilities), clinical scholar track (patient care and scholarship), educator track (educational focus but with scholarship component), research track (research focus but may include educational activities), and tenure track. Promotion along all tracks is determined by contributions to education, research/ scholarship, and service as appropriate to each track ${ }^{5}$.

As originally conceived, the mission-based funding allocation model recognizes primarily efforts of tenure track faculty, who received credit for educational activities plus are eligible for the 0.35 FTE research incentive. However, educator track and clinical scholar track are also eligible for the research incentive component. All tracks accrue credit to their department for any educational contributions, which are valued as the weighted mean salary benchmark for that department. Thus, it is appropriate (and expected) that research and clinical faculty be recognized for their educational contributions to the department. It is also anticipated that research track faculty perform significant service as representatives of the department, and the department is provided with a research service allocation of $0.035 \mathrm{FTE}$ (10\% of the 0.35 FTE research effort).

Additional allocations to departments

In addition to funds aligned with faculty activities, additional funds are also allocated to support department administrative infrastructure and general operations; these funds are determined in large part by the size of the department. Similarly, the department chair receives an allocation for her of his 
administrative duties that comprises a floor (0.1FTE) plus increments for each faculty member in the department (in larger departments, this may be divided among division directors). Other stateallocated funds outside the model that may be directly allocated to individual faculty include compensation for roles such as director of a school-based core, program, center, or institute, or for a 'super-educator' who may be critical for the operations of the medical school curriculum. Other examples include faculty serving in administrative role who may report to the dean or executive vice chancellor.

How do model-allocated funds translate into faculty salaries?

The primary driver for state funds coming to a department as an annual block grant is the cumulative activities of the faculty. Because these activities are known, it is theoretically possible to calculate actual values associated with the activities to determine an individual's 'value'. An example of this is presented in Figure 2. This figure compares the valuation of combined research, educational and service activities for an associate professor on the tenure track with that of an individual of comparable rank on the research track. This example assumes that both individuals maintain some administrative and/or educational activities totaling 0.3 FTE, which might include a core directorship, mentoring PhD and/or MS students, a course directorship, and UME and/or graduate student didactic teaching. The benchmark salary for a tenure track associate professor using 2016-2017 data was $\$ 120,000$ per year excluding fringe benefits.

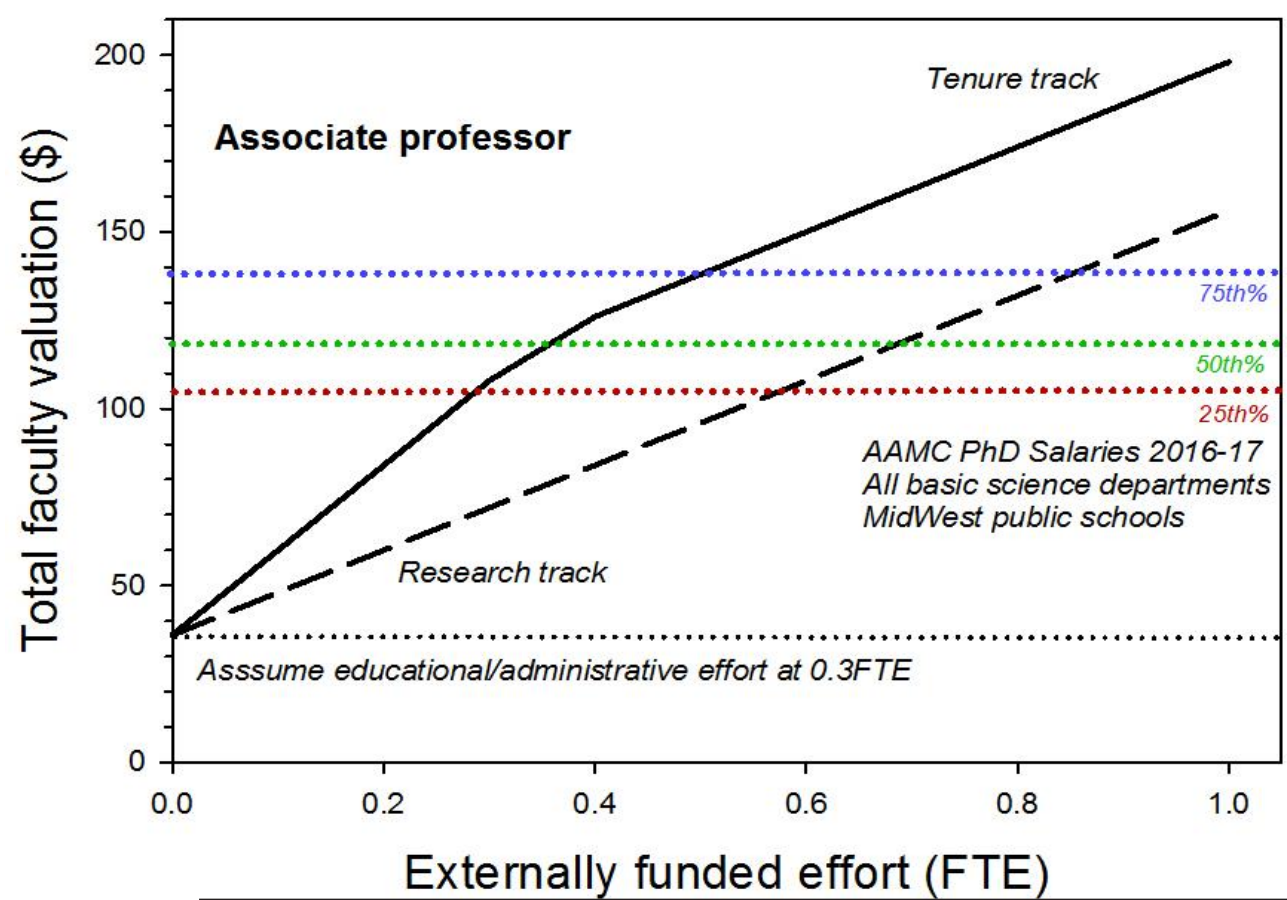

Figure 2. Hypothetical example of the relation between externally funded research effort and valuation of a tenure track or research track faculty member under the mission-based allocation model. 
In the absence of any research funding, the value of the 0.3 FTE in nonresearch activities brings $\$ 36,000$ to the department, and this increases directly as a function of funded research effort. While value for a research track faculty increases linearly, that of the tenure track faculty increases more steeply due to the 'research incentive' contribution to the department. Accordingly, a value corresponding to the $50^{\text {th }}$ percentile of AAMC salary rankings is achieved when externally funded effort attains 0.35 FTE for tenure track, or 0.7 FTE research track.

According to this approach, it is also possible for faculty valuation to significantly exceed the median benchmark salary. As a tenure track faculty member increases his or her externally funded effort, value to the department continues to increase such that, at $70 \%$ external funding, value is approximately $\$ 160,000$ for an associate professor (well above the 2016-2017 AAMC median benchmark of $\sim \$ 120,000)$. For research track faculty, salaries may include compensation for any educational activities or administrative roles, and value increases in direct proportion to externally funded effort.

It may be tempting for a faculty member to see the computed valuation as their 'true worth' or for a chair to simply use the school's calculations to determine a faculty member's salary. This is discouraged for the following reasons:

- Departments require additional funds for expenses such as bridging a faculty member's salary when funding is lost; assuming every faculty member holds a 5-year R01 and that not every renewal application is successful, up to $20 \%$ of faculty are at risk of losing salary support in a given year. NIH does not permit directly linking salary support to funding, so additional salary support is necessary to maintain salaries at an accepted level when funding is lost.

- Even in the absence of a principal investigator losing a major grant, effort may vary as a result of loss of grants where investigators play a more minor role. Hence, having a mechanism by which to 'smooth' normally occurring peaks and valleys is advantageous.

- The value placed on any given faculty member could vary quite a bit as a result of funding loss or, for that matter, dramatic success. Most Human Resource departments have policies that discourage massive year to year variance, or wages that are substantially above or below certain norms without rigorous justification.

Because of these and other considerations, departments are encouraged to employ a compensation plan that returns to the externally funded faculty member state funds that are less than the actual value realized by the department under the allocation model. Thus, in the example above where 0.35 FTE of funded effort was sufficient to attain valuation comparable to the AAMC $50^{\text {th }}$ percentile, it would be appropriate instead to require 0.4 or 0.45 FTE funded effort to achieve that level of compensation. The result would be a displacement of some state funds by externally funded effort, and those state funds would be held centrally for the purpose of providing a pool of reserve funds to maintain faculty salaries during a funding hiatus.

In the case of individuals who are highly successful in obtaining external funding, the bulk of their salary normally would be derived from committed effort 
on grants. However, these individuals generally are high performers typically engaged in a greater array of activities, and may be susceptible to recruitment to other institutions. In such instances, salaries exceeding the median benchmark seem quite appropriate and the availability of some of the displaced school dollars provides a mechanism for achieving the higher salary.

Clearly, the reliance of individual departments on retention of funds derived from mission-based activities funded under the allocation model will vary as a function of resources available from other sources such as endowment, clinical revenue, commercial enterprises and so forth. Thus, one size does not fit all and the appropriateness of trying to impose a single plan for all departments would not be feasible. At the annual departmental evaluations, we ask chairs to provide a 5-year business plan, as well as a copy of the department's compensation plan, so that we can be better assured of the department's financial sustainability.

Feasibility of mission-based allocation model expectations

A question that arises is whether the expectations of the model can be realistically met within the current funding climate. We have conducted assessments over time to determine the feasibility of maintaining an external funding level sufficient to support faculty salaries at competitive levels. Figure 3 shows external effort of one of our foundational sciences departments for the period from July 2014 through April 2018. During this period, all effort for faculty varied from about 0.57 to 0.45 , well above the model's benchmark value of 0.35 FTE (red line). Similarly, the 'capped' effort (i.e., the highest level of effort capped at $0.35 \mathrm{FTE}$, thus reflecting funds distributed to the department as the research incentive com ponent) varied from about 0.34 to about 0.28 FTE. Accordingly, even in the absence of other

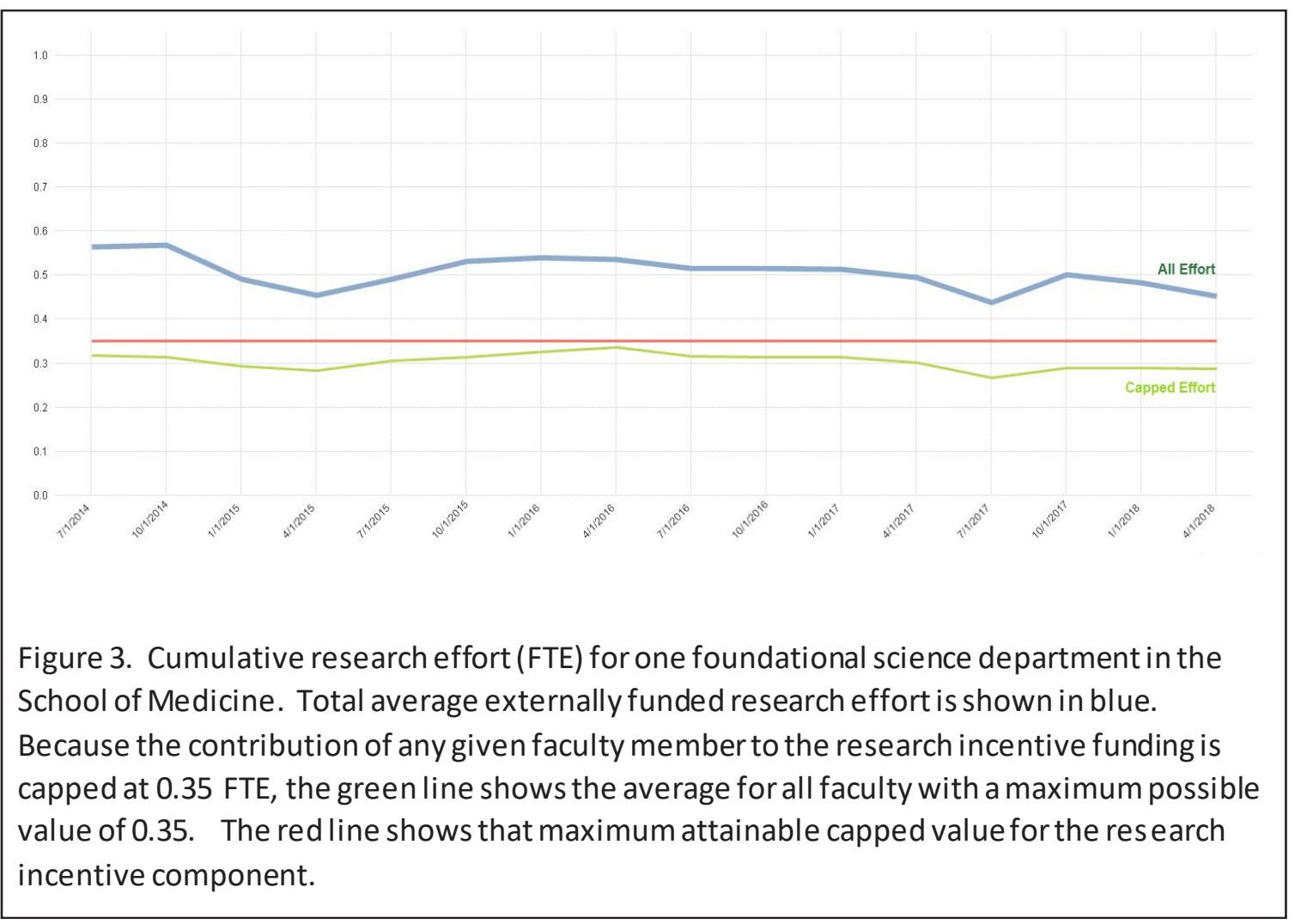


resources, we would predict that between research incentive funds and funds released from individuals with effort exceeding 0.35 FTE, that this department would have no difficulty in maintaining a competitive salary structure.

\section{Are we moving the needle?}

A rationale for implementing mission-based funding is to drive behavior in directions that are well aligned with the goals of the school. One of our major goals is to enhance research programs, and to do so requires higher levels of external support, with a focus on funding from the NIH. Increased funding can be achieved by submitting greater numbers of applications, by submitting applications requesting higher levels of funding, or both. Regarding applications' budgets, historically KU SOM grant application budgets generally have been lower than those of peer institutions (data from Academic Analytics). This is likely due in part to investigators underestimating their actual effort on projects; absent pressures to fully account for one's effort, a smaller budget may be seen as a selling point with reviewers.

If the goal of enhancing research activity is succeeding, then one would expect to see initially greater numbers of applications, and larger amounts requested as investigators depict their actual effort on grants more realistically. Since implementing the allocation model in Fiscal Year 2016 (which began July 2015), the numbers of submitted applications fluctuated but did hit a 6-year high in FY18 (Figure 4, top). The size of requested budgets showed a substantial increase in FY16, which sustained through FY18 (Figure 4, center). The extent to which the larger requested budgets and numbers of applications have affected overall funding levels is complex, and monitoring over a longer period of time will be necessary in order to fully appreciate the impact. Nonetheless, after seeing a drop in overall funding in 2015 attributable to conclusion of some major grants and some faculty departures, therehas been a steady increase in funding since implementing the model and FY18 showed a 6-year high in overall NIH funding (Figure 4 bottom).

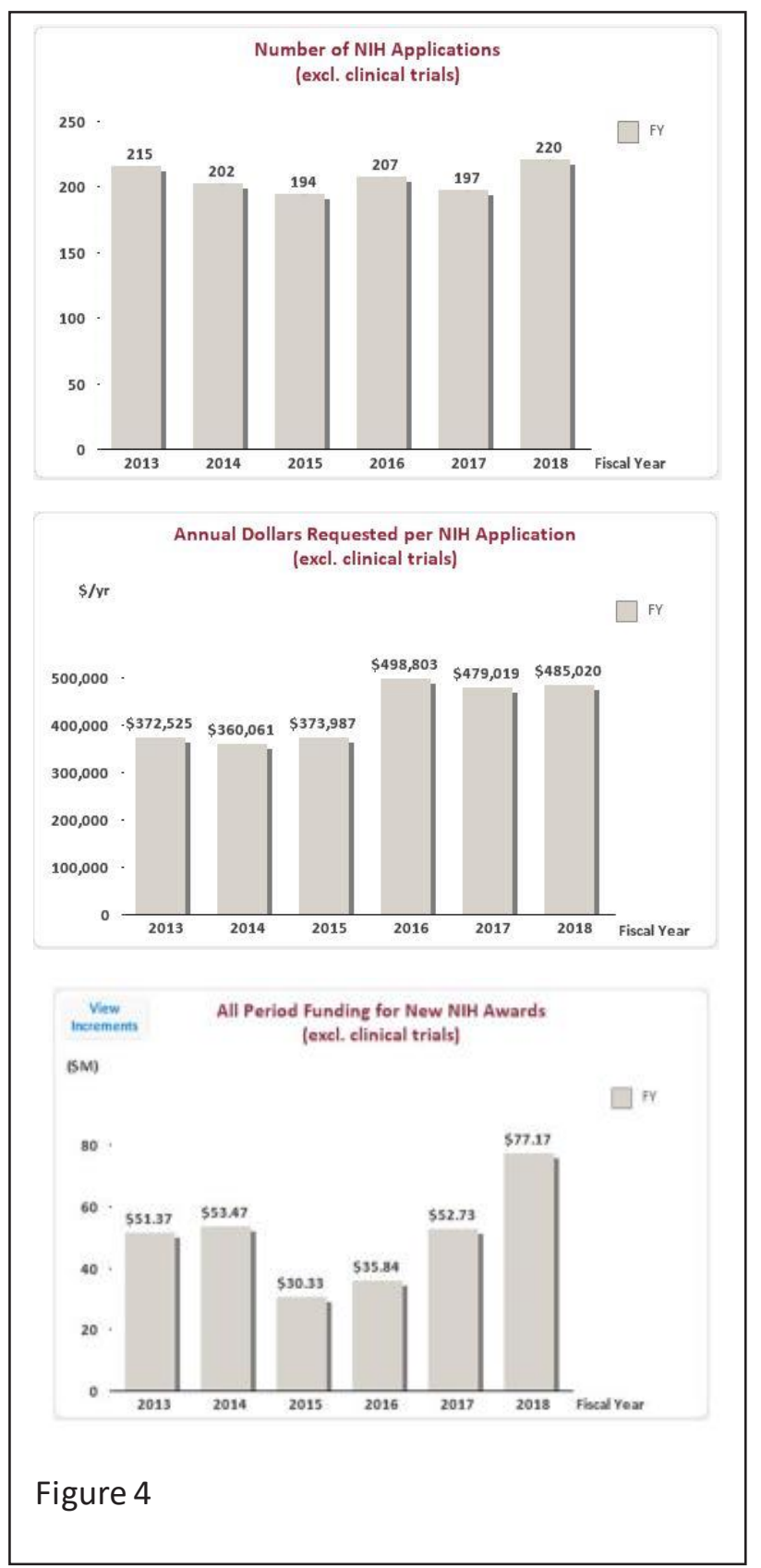




\section{Implications for departmental operations}

The implementation of missionbased funding has significant implications regarding the operations of clinical and basic science departments. As regards clinical departments at the KU SOM, some funds from the clinical practice are available to support the research and educational missions. It is expected that these, as well as other funding sources such as endowment, be used to further enhance programs that advance the objectives of the school. These alternative funding sources should be applied to augment departmental finances in a manner that provides enhanced flexibility within the context of fulfilling the school's and department's missions.

Typically, basic foundational science departments operate with a tighter margin and, while endowment funds are often available, these departments lack the financial flexibility of clinical departments. In some cases, educational activities can be significant model allocation sources, such as when there are programs with large numbers of masters' or PhD students (an $\mathrm{MPH}$ program would be an example). This generally does not apply to traditional wet-lab programs where the capacity to accommodate large numbers of students engaged in laboratory training is limited.

The assumptions included under the mission-based funding model provide some insight into how basic foundational science departments may evolve in the future. The expectation is that all faculty maintain active research programs unless they are dedicated administrators or key educators. In a department that is operating optimally, faculty will maintain $\geq 0.4$ FTE externally funded research effort. Clearly, if a significant number of faculty are chronically un- or underfunded, this will have dramatic impact on departmental finances and could jeopardize financial support of all faculty; regular departmental reviews, annual faculty reviews and assessments, post-tenure review, and mechanisms to fairly implement salary adjustments that align with changes in productivity need to be in place.

There is a high probability that all researchers, at one time or another, will experience a hiatus in external funding. The impact of a funding lapse for a given faculty member can be mitigated by maintaining greater numbers of active awards as PI, and by serving on multiple other awards as co-Investigator. Nonetheless, funding lapses remain probable, and it is essential to have mechanisms in place to ensure that a temporary loss of funds does not mean firing valuable and highly trained staff or interrupting training of a graduate student, post-doc or fellow. Once a laboratory is shuttered, the likelihood that an investigator will be able to resume an active externally funded research program is greatly diminished. Accordingly, a key consideration is that KUSOM maintains a robust bridging program to provide interim laboratory support until alternative funding may be secured. This program commits those funds necessary to ensure that essential staff are maintained at a level so that productivity continues. Three times a year, applications for bridging support are accepted and reviewed by the SOM Research Committee, and the investigator's and department's current financial resources assessed. If requirements, such as submitting applications for external funding, are met, and the Committee 
feels the application is meritorious, a recommendation for funding is made to the Executive Dean and support is provided. However, because interim faculty salary support is the responsibility of the department, this necessitates availability of pooled departmental funds.

While there is general agreement that the values associated with various activities are justifiable, the transition from historical funding to model-based funding was not easy in all cases. Different departments experienced increases or decreases in allocations relative to prior years depending upon whether or not they were historically, on average, over- or under-funded. Those that had been most generously overfunded saw the greatest impact of the transition to the new model. Given the significant implications that budget shifts have on personnel and department operations, a decision was made to 'smooth' the transition to the new allocation value over 3 years, in effect temporarily shifting some funds from those with increases to those with decreases. Additional challenges have come as tracking tools have improved leading to better data that can impact distributions, and better understanding as to how we categorize and value certain activities. Clearly, a stable model free from unanticipated excursions in valuation is the goal.

It is also important to note that state funds represent only a fraction of the overall financial portfolio of the KU SOM. The contemporary medical school and its departments are forced to look increasingly to funds other than state allocations, which may include endowment, tuition and fees, contracts, commercialization, services, revenue from IP, and so forth. Hence, while the mission-based allocation model provides a means for aligning limited state funding with the true missions of the school, chairs must be prepared to identify and seek funding opportunities from what may have been considered as non-traditional sources under the historic funding model.

\section{Summary}

With financial pressure rising with reduced state funding, KU SOM sought an alternative means for distributing funding that was better aligned with its missions, and a missionbased funding allocation model was developed. The mission-based model directly aligns departmental compensation to performance. Accordingly, it places greater onus on faculty to seek and maintain external funding and to participate aggressively in educational activities. KU SOM believes that this approach is having transformational impact on faculty engagement. Nonetheless, there is also a need to monitor and adjust elements of the model as situations demand in order to attain a new equilibrium and financial sustainability. 


\section{References}

1. https://www.nytimes.com/2016/11/06/education/edlife/college-budgets-affectyour-education-but-its-not-all-bad-news.html ;

2. https://www.educationnext.org/higher-ed-lower-spending-as-states-cut-backwhere-has-money-gone/ ;

3. https://www.insidehighered.com/news/2018/01/22/state-support-higher-edgrows-16-percent-2018

4. Stites S, Vansaghi L, Pingleton S, Cox G, Paolo A. Aligning compensation with education: design and implementation of the Educational Value Unit (EVU) system in an academic internal medicine department. Acad Med. 2005 Dec;80(12):1100-6. PubMed PMID: 16306280. 